\title{
Liposome-encapsulated Recombinant Human Cu/Zn Superoxide-dismutase
}

National Cancer Institute

\section{Source}

National Cancer Institute. Liposome-encapsulated Recombinant Human Cu/Zn

Superoxide-dismutase. NCI Thesaurus. Code C99764.

A topical hydrophilic gel containing a recombinant form of the human Cu/Zn superoxide dismutase (SOD1), a cytoplasmic antioxidant enzyme, encapsulated in liposomes with potential anti-inflammatory and adjuvant activities. Upon application of liposomeencapsulated recombinant human Cu/Zn SOD as a thin film on the irradiated area, the recombinant SOD1 is released and scavenges free oxygen radicals, thereby protecting cells from oxidative stress. This may prevent radiation-induced dermatitis as well as other types of skin reactions. 